\title{
Ecoinvent 3: assessing water use in LCA and facilitating water footprinting
}

\section{Journal Article}

Author(s):

Pfister, Stephan (D); Vionnet, Samuel; Levova, Tereza; Humbert, Sebastien

Publication date:

2016-09

Permanent link:

https://doi.org/10.3929/ethz-b-000103122

Rights / license:

In Copyright - Non-Commercial Use Permitted

Originally published in:

The International Journal of Life Cycle Assessment 21(9), https://doi.org/10.1007/s11367-015-0937-0 
This is a reprint. The final publication is available at Springer via http://dx.doi.org/10.1007/s11367-015-0937-0

(3)

(1) 5

Ecoinvent 3: assessing water use in LCA and

\section{facilitating water footprinting}

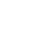

Stephan Pfister, Samuel Vionnet, Tereza Levova, Sebastien Humbert

0

S. Pfister $(\bowtie)$

2 e-mail: stephan.pfister@ifu.baug.ethz.ch

Tel: $+\mathbf{+ 4 1 4 4 6 3 3 7 5 7 1}$

Fax: +41 446331579

5

S. Pfister

ETH Zurich, Institute of Environmental Engineering, 8093 Zurich, Switzerland

Aveny GmbH, Zurich, Switzerland

S. Vionnet

20 Quantis International, Lausanne

1 T. Levova

22 ecoinvent Centre, Technoparkstrasse 1, 8005 Zürich, Switzerland

23 S. Humbert

24 Quantis International, Lausanne 
Purpose Water footprinting and the assessment of water use in life cycle assessment have become of major interest in sustainability assessments. Various initiatives for combining water resource issues with consumption of products and services have been initiated in the last decade. However, comprehensive databases fulfilling the requirements for addressing these issues have been lacking and are necessary to facilitate efficient and consistent assessments of products and services. To this purpose, ecoinvent focused on integrating appropriate water use data into version 3 , since previously water use data has been inconsistently reported and some essential flows were missing. This paper describes the structure of the water use data in ecoinvent, how the data has been compiled and the way it can be used for water footprinting.

Methods The main changes required for proper assessment of water use are the addition of environmental and product flows in order to allow a water balance over each process. This is in accordance with the strict paradigm in ecoinvent 3 to focus on mass balances, which requires the inclusion of water contents of all products (also for e.g. waste water flows), as well as emissions of water to soil, air and various water bodies. Water inputs from air (e.g. rainwater harvesting) is introduced but is not yet used by any activity.

Results Ecoinvent version 3.1 consistently includes the relevant flows to address water use in LCA and calculate water footprints on the product level for most processes including uncertainty information. Although some problems regarding data quality and spatial resolution remain, this is an important step forward and can limit efforts for detailed data collection to the most sensitive processes in the product system. With the combination of data on water use and emissions to water for each process, concentration and corresponding water classes can also be calculated and assessed with existing impact assessment methods.

Keywords water use $\bullet$ water footprint $\bullet$ inventory 


\section{Introduction}

Water is vital for humans and the ecosystem, and it is under pressure although being a globally abundant, renewable resource (Rockström et al. 2009). Distribution of water use and availability as well as the enlarged future population is threatening life in many regions (Ridoutt and Pfister 2010a), and therefore reducing water use and consumption is one of the most important actions for sustainable consumption. In this context, several initiatives to create public awareness and to facilitate proper assessment and communication of water problems and risks in products and services have been initiated, such as the water working group of UNEP-SETAC Life Cycle Initiative (WULCA, Koehler 2008). The need for good water use data has been raised in many conferences and publications in last few years, in particular by the CEO Water Mandate (Morrison and Schulte 2010), the water footprint network (WFN; Hoekstra et al. 2011) and UNEP (Mc Glade et al. 2012). Also within LCA the demand for assessing water use properly has become more important as LCA per definition tries to address all relevant environmental impacts (ISO 2006a,b). The structure required for properly assessing impacts of water use is based on the distinction between consumptive water use (local loss of freshwater by evaporation, product integration and release in a different watershed or to sea) and degradative water use (quality change only) as well as between in-stream and off-stream use (Bayart et al. 2010, Pfister et al. 2009). While ecoinvent data before version 3 were mainly accounting for water withdrawal (combination of consumptive and degradative off-stream use), freshwater consumption had not been represented in the database. In response, different publications addressed these lacks of data for the agricultural and power production sectors (e.g. Scown et al. 2011, Pfister et al. 2011a/b, Stoessel et al. 2012). However, no synchronized database has been created that allows to consistently and transparently assess water use within the LCA framework (Kounina et al. 2013). The GaBi database (PE 2012) includes data for assessing water consumption consistently but without required transparency on unit process level and uncertainty information. Furthermore, consistent integration into a process-based LCA database enables advanced water footprint assessment including water quality aspects, such as suggested in various papers (Bayart et al. 2010, Ridoutt and Pfister 2010b, Berger and Finkbeiner 2010, Boulay et al. 2011, Ridoutt and Pfister 2013) in order to provide an LCAbased alternative to the "grey water footprint" approach described by Hoekstra et al. (2011). The need to have data for water footprinting is also influenced by the fact that the International Organization for Standardization (ISO) developed a water footprint standard ISO 14046 (ISO 2014). 
One main challenge is the need for regionalized inventory and impact assessment. While a high spatial resolution is preferable from a scientific point of view (Pfister et al. 2011b), practitioners are often satisfied with a country level resolution for background systems (Vionnet et al. 2012), since time constraints might not allow for advanced regionalization. Proper integration of spatial information is an additional demand, and use of a country level resolution seems to be the state-of-the-art practice for full life cycle assessments (especially the background systems). An additional feature helping regionalization of supply chains is the automatic geographic linking of inputs from technosphere through the market activities in ecoinvent (Weidema et al. 2013). This means that if a process from China uses Chinese electricity, the electricity input will be automatically adjusted to US electricity if the process location is changed to US when creating a new dataset for updates of the ecoinvent database.

The ecoinvent database v3 structure serves the need for data that allows companies and public agencies to better assess their businesses, products and activities (especially their supply chain) regarding impacts on water resources for managing and eventually reducing them. The update of ecoinvent regarding the water inventory is based on the Quantis Water Database (WDB) project that was launched in collaboration with ecoinvent in end of 2010 together with eight private companies (Veolia Environnement, Natura, Steelcase, Kraft, Danone, Molson Coors, Unilever, L'Oréal) and ended in early 2012. To quantify water inputs and outputs, the WDB was built on the ecoinvent 2.2 water data and typical water consumption rates for different industries based on literature data. Additionally, primary data was collected from literature for several hundred processes. The details are described in Vionnet et al. (2012). The resulting inventory database was used to update inventories that existed in ecoinvent v2.2 for ecoinvent v.3.0. Ecoinvent v3.1 updated all processes/activities of version 3.0 to the same standard based on the procedure of the WDB.

In this paper we describe the data structure and summarize data sources as well as procedures to define water flows in ecoinvent v3.1. We also discuss the shortcomings and uncertainties related to the data, and we illustrate the use of ecoinvent data for water footprinting and water use assessment in LCA. 
107 The structure of ecoinvent version 3 has been considerably changed since version 2 as described in

108 Weidema et al. (2013): Main changes are the consistent inclusion of mass balances and the avoidance of 109 allocation in multi-output processes on the unit process level. As water has not been integrated 110 consistently before version 3 , changes are less relevant than the additions. While data required to assess 111 water withdrawal, such as in-stream use (turbined water), substance and heat emissions to water (water 112 pollution) and in-stream storage ("occupation of water bodies"; e.g. for power production) have been 113 partially present, the output flows (emission to water and air) to quantify water consumption and 114 degradative water use have been missing (Figure 1). Therefore, most water use impact assessment 115 methods could not connect to the inventory and so the approach taken in the WDB is used to update 116 existing ecoinvent v2.2 data, which allows for more detailed inventory and consequently impact 117 assessment of water consumption. Unfortunately, the thermal emissions to water are so far excluded in 118 version 3 of ecoinvent, but temperature can be added in the future as a property of the water flows to 119 calculate heat emissions to water. Substance emissions, which might be relevant in assessing a water 120 degradation footprint, are reported separately in ecoinvent.

\section{1 [FIGURE 1]}

\section{$122 \quad 2.1$ Structure of water flows in ecoinvent.}

123 Water flows in ecoinvent are extended compared to the flows existing in version 2 in order to allow for a 124 complete water balance and therefore also the quantification of water consumption. The following flows are captured in ecoinvent (environmental flows are summarized in Table 1 and conceptualized in Figure 2). 
- In air: This flow refers to precipitation collected from air. It is mainly associated with rainwater harvesting and in most cases is not relevant. In agriculture, only the rainwater collected within

- In water: The most common exchange with the environment is input of water from natural water bodies. These inputs are distinguished as fresh water and salt water. Fresh water has origins within a lake, a river, the ground or is unspecified (if the origin is not defined). Salt water flows can occur from a sea or brackish water. Furthermore, cooling water and turbined water are separated even though they are not actually different flows from the previously mentioned ones (they are inherited from datasets of ecoinvent 2). They represent a description of the process they are used in. Historically these water flows have been used since the process level has not been detailed enough. New datasets should avoid cooling and turbined water flows.

- Products: This is the flow from another process in the system (technosphere flow). Each product has water content ("water in wet mass") and therefore can be used to balance the water flows for all inputs and outputs. This is especially important for water transport and treatment processes (e.g. water 
154 generated without water consumption for non-irrigated crops ("biogenic" water consumption).

- If the exact origin and/or destination of the freshwater exchanges are unknown, they are entered as inputs from and/or outputs to the environmental sub-compartment 'water, unspecified'.

\section{Water Outputs:}

- To air: Water evaporated or evapotranspirated to air is generally the most relevant flow of water consumption. The ecoinvent structure distinguishes between different locations of the emissions based on population densities and has a separate flow for emissions in high altitudes (mainly for airplanes). For emissions of water, this distinction does not matter as no impact of the emission as such is modelled (no pollution).

- To water: Water releases are captured as flows to water bodies. If water is released to artificial ponds or infiltrated, these processes should be modelled as separate activities, reporting flows to ground and surface water as well as evaporation. Ecoinvent v3.1 contains water flows to surface water, sea, groundwater and as unspecified (where no further information is available).

- Products: As for the inputs, the water in wet mass is quantified as a property of the product and can be translated into a water flow going to another process in the system (technosphere flow). However, this is not an environmental exchange.

Inputs and outputs are balanced in order to ensure mass conservation in each system process. Net freshwater consumption of an activity can be derived by deducting water outputs to freshwater bodies from freshwater inputs. The part of salt water evaporated can be balanced separately and deducted from the total evaporation. For agricultural processes, irrigation is modelled as a separate process in order to account for inputs of water sources, energy use and infrastructure. Depending on the level of detail of the dataset, storage and distribution of water to fields should be separate processes also describing evaporation seepage losses from different types of irrigation systems. This can be done manually and will be addressed in future versions of ecoinvent. The product (reference flow) that the "irrigation" activity delivers is a volume of irrigation water supplied to crops (and depending on the technology it has 
different infrastructure and losses). In ecoinvent 3.0 this was dealt with depending on the data providers of ecoinvent v3.0 datasets, however, for the processes of ecoinvent 2.2, water withdrawals in crop production have been replaced by water from irrigation activities. For version 3.1 , this has been consistently adjusted. The same concept should be applied for cooling processes, which should exist as separate processes if possible, but this is a future task of the ecoinvent database.

One limitation in the water balances is the potential chemical water formation (e.g. in a combustion process) or chemical binding of water in a product (e.g. in concrete), but generally these volumes are not very large. Another issue is that crop water content of non-irrigated crops or wood should be deducted from the overall water balance of a product, since the input of such "green water" is not modelled. In general these numbers are small compared to overall water consumption in crop production.

\section{[FIGURE 2]}

\section{[TABLE 1]}

\subsection{Database creation}

The main data source for water flows in ecoinvent 3 is the Quantis water database (WDB, Vionnet et al. 2012). The WDB updated and enhanced the water flows of existing ecoinvent 2.2 processes, and added 116 processes according to the described scheme, mainly in energy production. However, some adjustments were required and are explained below. Only existing processes in ecoinvent 2.2 have a consistent water inventory in ecoinvent 3.0, since additional processes have been inserted in parallel to the new scheme and have only been adjusted in ecoinvent 3.1.

\subsubsection{Processing of WDB data into ecoinvent format}

The WDB is structured in two parts. The first part is the raw data (elementary exchanges, mainly based on ecoinvent 2.2 data and data on consumptive use share of different industries), and the second part is the modelling to produce a custom and highly detailed inventory for each process. This modelling allows for the calculation, for example, of how much of the water is pumped in fossil, shallow or even depleted 
aquifers. The latter is at the limit of the impact assessment and is not supported in the ecoinvent inventory in order to keep the inventory as simple as possible and the impact assessment possibilities flexible. The raw data of the first part of the Water Database is illustrated in Figure 2. This data is usually collected from various sources ranging from national or international statistics to companies or industrial association reports, and many sources are used by ecoinvent currently. The Water Database refined the information already contained in ecoinvent 2 with an additional data collection effort as described in detail in the WDB report (Vionnet et al. 2012) and summarized below.

212 A few main data sources are used for the three main categories by which we can classify the entirety of 213 ecoinvent activities: industrial, agricultural and electrical. For the industrial processes, a large portion of 214 data were derived based on Byers et al. (2002) that allowed for updating more than forty processes, 215 mostly chemicals and materials production. Most of the information found in addition to Byers et al. 216 (2002) did not clearly mention the consumption share of the water used. This consumption share is fairly 217 important in order to assess the output water as well as the amount of water resource that is no longer available to other users (most impact assessment methods for water use require this information).

219 Therefore, this information has been collected when possible. However, for some processes, default consumption rates are applied based on Schaffer et al. (2008) and Statistics Canada (2007). For agricultural processes, most of the data available was in fact the consumed water as taken from Pfister et al. (2011b) and processed according to Pfister and Bayer (2014) for crops and Siebert and Doell (2010)

223 for grass and pasture. To calculate the water input (irrigation amount), an irrigation efficiency value was applied to the consumed water depending on country specific irrigation efficiencies (Siebert et al. 2010).

225 Lastly, water consumption in electricity production was refined based on Scown et al. (2011) for thermoelectric power and is based on the hydroelectric processes in Pfister et al. (2011a). Further details are presented in the SI and available in Vionnet et al. (2012).

Water supply processes are introduced for industry and domestic users (activities "tap water" and "cooling water") and for agriculture (activity "irrigation"). These flows are incorporated in ecoinvent as technosphere flows as they represent a separate independent activity and, thus, can also be adjusted on a case-by-case basis depending on the water supply system. A typical activity will have water supply defined as a separate activity as well as a water discharge activity (a waste water treatment process most 
234 instance the irrigation input is modelled as a technosphere input since this irrigation requires energy, 235 infrastructure, pipes, pumps, and implies losses of water during its transportation (Faist Emmenegger et 236 al. 2011). However its output water from the field is emitted directly to environment either to the 237 atmosphere (evaporated) or to the soil. Consequently, crop cultivation does not directly contain these 238 flows, but the irrigation process does. On the other hand, crop cultivation might cause changes in natural 239 water availability through change in soil moisture (green water), which should be determined by land use 240 impact assessment (Núñez et al. 2013) and not as an inventory flow.

\subsubsection{Consistency of water balance in ecoinvent v3.1 and known issues with v3.0}

Since new datasets were not updated for water flows in ecoinvent 3.0, many new electricity production datasets for hydro power lacked an output of water, even though they did have an input for turbined water. In ecoinvent v3.1, the water balance is corrected by adding the water output to these datasets (together with improvements in water balances for $>2000$ unit processes). In SimaPro 8.01 (PRéConsultants 2014) with ecoinvent v3.0, turbined water inputs were not assessed in the water balance while outputs were assessed as negative consumption. This led to the artefact that run-of-the-river hydropower production that was updated in ecoinvent 3.0 caused significant negative impact, which is a falsehood of the modelling and needed to be corrected manually. This is corrected in SimaPro 8.04 with ecoinvent 3.1 .

\subsection{Uncertainty information}

253 The uncertainties of the flows of an activity are determined using the pedigree matrix as described in 254 Weidema et al. (2013) and can be converted to k-values (based on Slob 1994): the expected value divided and multiplied by $\mathrm{k}$ includes the $95 \%$ confidence interval and can be calculated as $\mathrm{k}=\mathrm{e}^{\left(1.96^{*} \mathrm{sd} \_\mathrm{ln}\right)}$, where sd_ln is the standard deviation of the ln-transformed values (assuming a log-normal distribution). For water flows, the "basic uncertainty" is higher compared to the standard k-value, which is for most flows

$258 \mathrm{k}=1.05$ and reflects the relatively high uncertainty of water flows in ecoinvent 3.1. Especially important for the water use of agricultural processes is the spatial variability of climate and, consequently, irrigation water flows. This uncertainty should be reported in the uncertainty value for the input of irrigation water 
in new datasets (given that it is modelled as a separate process), because it is only partially accounted for by the "basic uncertainty" value. The uncertainty parameters are summarized in Table 2.

263 [Table 2]

\subsection{Regionalization}

266 For water use, regional aspects are essential for impact assessment. Although ecoinvent 3 has the 267 structure to include any spatial detail (e.g. countries, watersheds, coordinates), the potential of this feature 268 is not fully used. The main reason for this is that ecoinvent only includes reviewed datasets with a full list 269 of environmental exchanges and, therefore, cannot include different levels of spatial details for different 270 emissions or resource consumptions. This means that especially for agriculture, a large gap exists 271 between existing water consumption data (Pfister et al. 2011b) that have been integrated in the WDB and 272 ecoinvent inventory coverage. In most cases, the activities represent a global average or are specified on a country level. For such datasets, the variability is considered in the uncertainty assessment.

274 Of relevance for industrial processes is also water consumption in metal production, where ore production 275 is typically concentrated in a few places in the world and not generally found in the location of smelting.

276 This is accounted for on country level in the database based on ore origins. New activities can be included 277 e.g. by copying existing datasets and adjusting the water consumption and location, but this requires manual effort.

\subsection{Application of data for LCA and water footprint}

281 Water issues in LCA and water footprinting can be separated in quantitative (water scarcity) and 282 degradative (pollution) concerns. Quantitative assessments are based on volumetric water flows, in most 283 cases using the net freshwater consumption, which can be calculated as described in section 2.1. Quality 284 issues to be considered in water footprinting (ISO 2014) are addressed by assessing emissions to water.

285 Assessing water use with ecoinvent v3.1 following a full LCA is possible, for instance, with SimaPro 

adjusting the location of the irrigation activity and the irrigation water amount. As an example, we analysed wheat in Egypt and copied the transformation activity "wheat grain, Spain, wheat production" and the transformation activity "irrigation, Spain, processing" and saved it as "wheat grain, Egypt, wheat production" and "irrigation, Egypt, processing". SimaPro 8.04 assesses the impacts of water consumption based on the country location by defining separate environmental exchanges for each country and type of water resource (inputs from freshwater and outputs to freshwater) and nine integrated methods to assess these flows on country level. We therefore adjusted the water input to the irrigation process in the Egyptian production from Spanish groundwater and river water to Egyptian ones. In the wheat production activity for Egypt, the respective irrigation process is used and the water volume for $1 \mathrm{~kg}$ of wheat is changed from $0.71 \mathrm{~m}^{3}$ in Spain to $1.02 \mathrm{~m}^{3}$ in Egypt based on the deficit irrigation number provided by Pfister et al. (2011b). For impact assessment, we selected the method resulting in ReCiPe points (Pfister et al. 2011a), which is among the integrated methods in SimaPro 8.04. This integration of LCIA methods has not been provided by ecoinvent yet.

301 Since power production and tap water are important processes in many activities, we also show results for four different options and most relevant flows and contributing activities in the supporting information.

303 Due to current limitations of available software to utilize the full set of features in the new ecoinvent version, we used the WDB to illustrate the proper use of inventory analysis for a more complex system. The results are largely consistent with ecoinvent v3.1, since the underlying data is the same. However, some differences are expected to arise from the new allocation structure in ecoinvent that are not reflected in the WDB, but the results are still helpful to demonstrate what is possible with ecoinvent v3.1 and suitable software solutions. 
313 Although ecoinvent version 3.0 updated all processes of ecoinvent v2.2 consistently in terms of water

314 flows, some of the completely new processes in ecoinvent 3.0 did not properly report water flows.

315 Especially the newly introduced power production activities of v3.0 have incorrect water balances and 316 therefore should not be used. Out of the 4087 processes in ecoinvent v2.2, 1450 had a complete water 317 balance in v3.0. This is accounting for most activities since many processes in ecoinvent v2.2 were market processes or transmission of electricity where water use is inexistent or marginal (further details in SI).

320 Ecoinvent v3.1 consistently improved the water balance correcting 2468 unit processes. This includes $321>1000$ water flows to each air and water (since the main issue with ecoinvent 3.0 was the input of 322 turbined water without an output to the environment) and > 1400 "tap water" inputs. A summary of the 323 changes is shown in the SI. Version 3.1 now has an acceptable water balance for most of the 7155 unit 324 processes (UPR, including the product water property) as presented in Table 3. For the $\sim 2000$ activities with water balances deviating by $>15 \%$, supply chain water consumption is typically more important, since when analysing each activity "cradle-to-gate" with the supply chain, only $\sim 2 \%$ of the inventory results had more than 5\% deviation (Figure S1). Most of these flows have a high product water content that partially explains this difference (since only the environmental flows are balanced in this analysis). A summary of the LCI results for the three different ecoinvent v3.1 models is presented in the SI (Figure S1).

331 However, there are still many agricultural processes missing in ecoinvent 3.1 (e.g. olives, peanuts or 332 millet) and only a few countries have specific datasets, while agriculture is responsible for $\sim 85 \%$ of 333 global water consumption (Shiklomanov 1999). Additional efforts are therefore required in the future for 334 proper assessment of agriculturally-based product water footprints. 
337 The results for wheat grain production show that all relevant water consumption is caused by irrigation,

338 which is modelled as separate activities in ecoinvent v3.1 (Figure 3). The differences in water 339 consumption and related environmental impacts are substantial and reflect the high spatial variability of 340 water consumption in crop production. Water consumed for Spanish wheat production is $\sim 70 \%$ of the 341 amount consumed for Egyptian production. When the water stress index (WSI, Pfister et al. 2009) is applied for midpoint assessment, the resulting difference between Egypt and Spain is a factor of 2, while

343 the endpoint characterization factors (Pfister et al. 2009 and 2011a) reveal a factor of $~ 6$ for human

344 health, $\sim 10$ for resources and $\sim 50$ for ecosystem quality (Figure 3 ). These results illustrate the need for a

345 combined assessment of regionalized inventories and impact, and they show how this can be analysed on

346 a country level in available, commercial LCA software.

347 When agricultural products are not important in the supply chain, results are often driven by power production. Therefore, we present the results of four different processes for tap water and power production in different countries in the SI (which can be directly assessed by ecoinvent processes and methods provided in SimaPro 8.04). For power production, turbined water use is the most important water flow, but typically this flow is balanced with release of the water back into the river (relatively small consumptive use). Therefore, decarbonized water consumed in cooling towers is as important as water evaporation in dams. For the case of tap water production, turbined water is equally important as water supplied to the water works, but it is again mainly non-consumptive. Since tap water has its water consumption primarily through incorporation into the product, the activities producing tap water are mainly important in terms of water consumption in this cradle-to-gate assessment, but they will have a lower impact in a cradle-to-grave assessment since most of the tap water is released back after treatment into natural water bodies.

[Figure 3] 
363 A bottle of water produced by Danone on the Evian production site is taken as an illustrative example.

364 The entire life cycle of the bottle is considered from raw material production (primary, secondary and

365 tertiary packaging), through the bottling plant, distribution, storage, use phase and end-of-life.

\section{6 [FIGURE 4]}

367 Figure 4 shows that most of the water entering the system of the bottled water is used for cooling 368 purposes, especially for energy use at the use stage, at the distribution/storage stage, for packaging 369 production and at the production site. The water that is being incorporated in the bottle of water is only 370 coming from groundwater (at the production site stage) and is included in the category "to products" as 371 well at the same life cycle stage. A consumer then drinks the water at the use stage, and it is thus 372 categorized as "from products". This water is eventually also considered to be consumed (emitted to air).

373 This is a simplification as water might be released after wastewater treatment, depending on how much of 374 the water is transpired by the user.

375 The bottle of water is an industrial product and, thus, it does not consume a lot of biomass in its life cycle.

376 The delta soil moisture is by consequence small, which would not be the case for sugar containing 377 beverages for example.

378 This inventory allows us to have a precise idea of where and how much water is entering our system and 379 how it is emitted back to the environment or to the technosphere. This vision is really useful in water 380 footprinting in order to optimize a system and focus on the most important life cycle stages. In addition, 381 when dealing with regionalization, this disaggregation of data is, for example, mandatory to apply regionalized characterization factors.

\subsection{Data gaps and uncertainties}

385 The massive extent of the ecoinvent database and limited data availability of water flows lead to many

386 uncertainties. Besides the data gaps of processes intrinsic to ecoinvent, data gaps are filled with estimates 387 and expert judgements. All this is reflected in the data sets but must be considered when carrying out 388 LCA or water footprints. Error propagation e.g. by Monte Carlo is still not applied as a standard 389 procedure in such studies. However, uncertainty assessment is especially relevant for water issues due to 
the geographic variability and generally relatively rough data quality. In addition, using processes from different locations as proxies is more delicate than for many other flows, particularly in the case of agricultural products. This must be kept in mind when using data from ecoinvent in addition to the general uncertainty reported for the processes.

A minor data gap issue is the missing flow of soil moisture change during the process (e.g. cultivation of potatoes) compared to the reference situation. Generally, this value can be assumed to be zero in the datasets since the difference of soil moisture of an activity's land use compared to the reference situation is difficult to model and also since the reference state is not clearly defined and has been an issue for land use in impact assessment (Mila i Canals et al. 2007). For rain-fed agriculture, it may be relevant, and the environmental exchange should be considered in future versions of ecoinvent based on data availability. Another flow that is relevant for the water footprint are the thermal emissions (Verones et al. 2010, Pfister and Suh 2015) that have been removed in version 3 and should be reintroduced to future versions in order to allow the impact assessment of heat releases to water. Water quality classes of water released to the environment (outputs), as suggested by Boulay et al. (2011), can be calculated from the substance and water emissions to water of each activity. For water inputs, quality classes depend on the natural environment and can therefore be characterized by impact assessment methods.

\subsection{Impact assessment}

Most impact assessment methods require information about spatial detail below country level (at least on the optimal scale) as further described in Kounina et al. (2013). As indicated in the case study, the flows can be assessed on the country level if impact assessment methods provide such data. For most methods, a combination of several environmental flows is required to properly address the respective water issue.

412 Some further distinction of flows such as differentiation of groundwater into shallow, deep and fossil, as 413 done in the WDB (Vionnet 2012), could be done on the impact assessment level: Based on most detailed 414 spatial information about foreground system processes or a detailed analysis of sensitive processes and 415 flows, inventory data should be assessed with respective best resolution characterization factors. This can 416 be done by using tools beyond the traditional LCA tools, e.g. with the concepts described in Mutel et al. 417 (2012) and summarized in the next section. 
420 Ecoinvent data is so far not differentiated on the watershed level nor does it include temporal aspects, which is, in principle, demanded by the ISO 14046 standard for a proper water footprint (ISO 2014) and requested by some impact assessment methods (Hoekstra et al. 2011, Pfister and Bayer 2014). However, currently this demand is not fulfilled, although it is technically possible. The amount of workload required to update all datasets consistently in a background database is very high, while more detailed analysis can be done already with existing tools for those processes that show a relevant contribution in a specific analysis. Therefore it is expected that the technical report of "Illustrative examples on how to apply ISO 14046" (ISO 2015- TR 14073) will show some examples that explicitly aggregate data in supply chains in order to make the ISO water footprint applicable in practice. This would make sense, since in most cases the background system can be simplified without changing the overall results. By means of uncertainty and sensitivity assessment, those activities within the system that require further attention can be adjusted to the best level of temporal and spatial resolution. Typically, agriculture and power production processes play a key role in production systems and therefore might require increased spatial and temporal detail. For the foreground system and important processes in the supply chain, the spatial information can be attached to any activity, and, therefore, watershed level data can be derived from country data by creating child processes. The structure of ecoinvent 3 (based on unit processes) allows for any geographical unit to be defined as an attribute (Weidema et al. 2013) and consequently for detecting water scarcity issues at any spatial detail. The temporal dimension is even more challenging, since so far only total water consumption over time is reported. As done for national average characterization factors (aggregated based on watershed data), annual water scarcity factors can also be derived, reflecting typical water consumption patterns, e.g. in agriculture, such as presented by Pfister and Bayer (2014) and therefore allowing temporal aspects to be accounted for. For more detailed assessment in space and time, spatial and temporal extension matrices can be applied to the water flows in order to differentiate aggregated LCI

443 flows into e.g watersheds and monthly flows (Mutel et al. 2011, Pfister et al. 2013). In any case, the level of detail needs to be defined in the goal and scope section of a water footprint study. Depending on the outcome of the TR 14073, ecoinvent v3.1 might be directly applied for the background system in a water 
446 footprint study complying with ISO 14046 or it needs to be enhanced by temporal and spatial extensions.

447 With such extensions, ecoinvent can also serve as basis for foreground system processes.

\section{4. Conclusions}

450 The presented data is a comprehensive collection of water use data on the process level and facilitates the proper assessment of water use within an LCA and water footprints beyond agricultural production.

452 Especially in LCA, but also in tools for eco-design and specific water footprint, this data is essential and leads to a cost-efficient way of assessing consumption choices and product design decisions with full transparency. It further enhances the effectiveness of investing in data collection by performing sensitivity analyses using ecoinvent data and only focus on the most relevant flows and processes generally location specific information for agricultural production.

457

458 Acknowledgements We thank Jean-Christophe Bligny and Jean-Jacques Beley from Danone for sharing 459 their data for the case study presented in this article, Guillaume Bourgault for analyzing the water balances of all ecoinvent processes as well as Justin Boucher and Catherine Raptis for English proof-

461 reading. We further thank the following individuals for their input: Annette Koehler, Emilia Moreno Ruiz, Brad Ridoutt, Stefanie Hellweg, Bo Weidema, Pascal Lesage and Lindsay Lessard. 
Bayart JB, Bulle C, Deschênes L, Margni M, Pfister S, Vince F, Koehler A (2010) A framework for assessing off-stream freshwater use in LCA. Int J Life Cycle Assess 15:439-453

Berger M, Finkbeiner M (2010) Water footprinting: How to assess water use in life cycle assessment? Sustainability 2:919-944

Boulay A-M, Bouchard C, Bulle C, Deschênes L, Margni M (2011) Categorizing water for LCA inventory. Int J Life Cycle Assess 16:639-651

Byers W, Lindgren G, Noling C, Peters D (2002) Industrial Water Management: A System Approach, Second Edition, John Wiley \& Sons, Inc., Hoboken, NJ, USA. American Institute of Chemical Engineers

Faist Emmenegger M, Pfister S, Koehler A, Giovanetti L, Arena A, Zah R (2011) Taking into account water use impacts in the LCA of biofuels: an Argentinean case study. Int J Life Cycle Assess 16:869-877.

Falkenmark M, Rockstrom J (2004) Balancing water for humans and nature: The new approach in ecohydrology. Earthscan, London

Goedkoop M, Heijungs R, Huijbregts MAJ, De Schryver A, Struijs J, van Zelm R (2009) ReCiPe 2008 -

ISO (2014). ISO 14046 Water footprint - Principles, requirements and guidelines. International Organization for Standardization, Geneva A new life cycle impact assessment methodology. Int J Life Cycle Assess 8:324-330. 
Koehler A (2008) Water use in LCA: Managing the planet's freshwater resources. Int J Life Cycle Assess $13: 451-455$

Kounina A, Margni M, Bayart JB, Boulay AM, Berger M, Bulle C, Frischknecht R, Koehler A, Mila-iCanals L, Motoshita M, Núñez M, Peters G, Pfister S, Ridoutt BG, van Zelm R, Verones F, Humbert S (2012) Review of methods addressing freshwater use in life cycle inventory and impact assessment. Int J Life Cycle Assess 18: 707-721.

McGlade J, Werner B, Young M, Matlock M, Jefferies D, Sonnemann G, Aldaya M, Pfister S, Berger, Farell C, Hyde K, Wackernagel M, Hoekstra A, Mathews R, Liu J, Ercin E, Weber JL, Alfieri A, Martinez-Lagunes R, Edens B, Schulte P, von Wirén-Lehr S, Gee D (2012). Measuring water use in a green economy, A Report of the Working Group on Water Efficiency to the International Resource Panel, UNEP (United Nations Environment Programme).

Milà i Canals L, Bauer C, Depestele J, Dubreuil A, Knuchel RF, Gaillard G, Michelsen O, Müller-Wenk R, Rydgren B (2007) Key elements in a framework for land use impact assessment within LCA. Int J Life Cycle Assess 12:5-15.

Morrison J, Schulte P (2010) Corporate water accounting - an analysis of methods and tools for measuring water use and its impacts, UNEP, The CEO Water Mandate, Pacific Institute

Mutel CL, Pfister S, Hellweg S (2012) GIS-Based Regionalized Life Cycle Assessment: How Big Is Small Enough? Methodology and Case Study of Electricity Generation. Environ Sci Technol 46:1096-1103

Núñez M, Pfister S, Roux P, Antón A (2013) Estimating Water Consumption of Potential Natural Vegetation on Global Dry Lands: Building an LCA Framework for Green Water Flows. Environ Sci Technol 47:12258-12265

PE (2012) GaBi 6, http://www.gabi-software.com/international/index/, PE INTERNATIONAL AG

Pfister S, Koehler A, Hellweg S (2009), Assessing the Environmental Impacts of Freshwater Consumption in LCA. Environ Sci Technol 43:4098-4104

Pfister S, Saner D, Koehler A (2011a) The environmental relevance of water consumption in global power production. Int J Life Cycle Assess 16: 580-591 
Pfister S, Bayer P, Koehler A, Hellweg S (2011b) Environmental impacts of water use in global crop production: hotspots and trade-offs with land use article. Environ Sci Technol, 45:5761-5768

Pfister S, Edens B, Graveland C, Lutter S, Mutel C, Raptis C (2013) Refine and test SEEAW and relevant water accounting parts of SEEA2012; D3.1 of the CREEA project (EC: FP7). Zurich/Den Haag/Vienna. http://www.ifu.ethz.ch/ESD/downloads/reports/CREEA_3_1.pdf

Pfister S, Bayer P (2014) Monthly water stress: spatially and temporally explicit consumptive water footprint of global crop production. J Clean Prod 73:52-62.

Pfister S, Suh S (2015) Environmental impacts of thermal emissions to freshwater: Spatially explicit fate and effect modeling for life cycle assessment and water footprinting. Int J Life Cycle Assess DOI: $10.1007 / \mathrm{s} 11367-015-0893-8$

Pfister S (2015) Water use (chapter 12). In: LCA Compendium - The Complete World of Life Cycle Assessment, series eds. Klöpffer W, Curran MA. Life Cycle Impact Assessment, eds. Hauschild M, Huijbregts M, Springer Dordrecht. ISBN 978-94-017-9743-6

PRéConsultants (2014) SimaPro 8. http://www.pre-sustainability.com/simapro8

Ridoutt BG, Pfister S (2010a) Reducing humanity’s water footprint. Environ Sci Technol 44:6019-6021

Ridoutt BG, Pfister S (2010b) A revised approach to water footprinting to make transparent the impacts of consumption and production on global freshwater scarcity. Glob Environ Chang 20:113-120

Ridoutt BG, Pfister S (2013) A new water footprint calculation method integrating consumptive and degradative water use into a single stand-alone weighted indicator. Int J Life Cycle Assess 18: 204-207

Rockström J, Steffen W, Noone K, Persson Å, Chapin FS, Lambin EF, Lenton TM, Scheffer M, Folke C, Schellnhuber HJ, Nykvist B, de Wit CA, Hughes T, van der Leeuw S, Rodhe H, Sörlin S, Snyder PK, Costanza R, Svedin U, Falkenmark M, Karlberg L, Corell RW, Fabry VJ, Hansen J, Walker B, Liverman D, Richardson K, Cruzen P, Foley JA (2009) A safe operating space for humanity. Nature 461:472-475

Rosenbaum RK, Bachmann TM et al. (2008) USEtox - The UNEP-SETAC toxicity model: recommended characterisation factors for human toxicity and freshwater ecotoxicity in Life Cycle Impact Assessment. Int J Life Cycle Assess 13:532-546 

Technol 45:2541-2553

Siebert S, Döll P (2010) Quantifying blue and green virtual water contents in global crop production as well as potential production losses without irrigation. J Hydrol 384:198-217

Siebert S, Burke J, Faures J, Frenken K, Hoogeveen J, Doll P, et al. (2010). Groundwater use for irrigation - a global inventory. Hydrol Earth Syst Sci 14:1863 - 1880.

Shiklomanov AI (1999) World water resources at the beginning of the 21st century International Hydrological Programme. St. Petersburg, State Hydrological Institute (SHI) / UNESCO.

Slob W (1994) Uncertainty Analysis in Multiplicative Models, Risk Anal 14:571-576

Statistics Canada (2007) Industrial Water Use, Statistics Canada. Accessed on 6 June 2013. http://www.statcan.gc.ca/pub/16-401-x/16-401-x2010001-eng.pdf

Stoessel F, Juraske R, Pfister S, Hellweg S (2012) Life Cycle Inventory and Carbon and Water FoodPrint of Fruits and Vegetables: Application to a Swiss Retailer. Environ Sci Technol, 46:3253-3262

Verones F, Hanafiah MM, Pfister S, Huijbregts MAJ, Pelletier GJ, Koehler, A (2010) Characterisation factors for thermal pollution in freshwater aquatic environments. Environ Sci Technol 44:9364-

Vionnet S, Lessard L, Offutt A, Levova T, Humbert, S (2012) Quantis Water Database - Technical report Quantis International, Lausanne Overview and methodology. Data quality guideline for the ecoinvent database version 3 . The ecoinvent Centre, St. Gallen 
Table 1: List of elementary flows relevant for water impact assessment and water footprint

\begin{tabular}{|c|c|c|c|c|}
\hline & Compartment & Sub-compartment & Flows & Units \\
\hline \multicolumn{5}{|c|}{ INPUTS } \\
\hline \multicolumn{5}{|c|}{ natural } \\
\hline & resource & in water & Water, cooling, unspecified natural origin & m3 \\
\hline & \multicolumn{4}{|l|}{ natural } \\
\hline & resource & in water & Water, lake & m3 \\
\hline & \multicolumn{4}{|l|}{ natural } \\
\hline & resource & in water & Water, river & m3 \\
\hline & \multicolumn{4}{|l|}{ natural } \\
\hline & resource & in water & Water, salt, ocean & m3 \\
\hline & \multicolumn{4}{|l|}{ natural } \\
\hline & resource & in water & Water, salt, sole & m3 \\
\hline & \multicolumn{4}{|l|}{ natural } \\
\hline & resource & in water & Water, turbine use, unspecified natural origin* & m3 \\
\hline & \multicolumn{4}{|l|}{ natural } \\
\hline & resource & in water & Water, unspecified natural origin & $\mathrm{m} 3$ \\
\hline & \multicolumn{4}{|l|}{ natural } \\
\hline & resource & in water & Water, well, in ground & m3 \\
\hline & resource & Land & Occupation, inland waterbody, unspecified & $\mathrm{m} 2 *$ year \\
\hline & natural & \multicolumn{3}{|c|}{ Transformation, from inland waterbody, } \\
\hline & resource & Land & unspecified & $\mathrm{m} 2$ \\
\hline & \multicolumn{2}{|l|}{ natural } & $\begin{array}{l}\text { Transformation, to inland waterbody, } \\
\text { unspecified* }\end{array}$ & $\mathrm{m} 2$ \\
\hline NEW & $\begin{array}{l}\text { natural } \\
\text { resource }\end{array}$ & in air & Water, in air & m3 \\
\hline \multicolumn{5}{|c|}{ OUTPUTS } \\
\hline & \multirow[t]{2}{*}{ air } & urban air close to ground & Water & m3 \\
\hline & & non-urban air or from high & & \\
\hline & air & stacks & Water & $\mathrm{m} 3$ \\
\hline & air & $\begin{array}{l}\text { low population density, } \\
\text { long-term }\end{array}$ & Water & m3 \\
\hline & air & $\begin{array}{l}\text { lower stratosphere + } \\
\text { upper troposphere }\end{array}$ & Water & m3 \\
\hline & air & unspecified & Water & m3 \\
\hline NEW & water & surface water & Water & m3 \\
\hline NEW & water & ocean & Water & m3 \\
\hline NEW & water & unspecified & Water & m3 \\
\hline NEW & water & ground & Water & m3 \\
\hline NEW & water & ground-, long-term & Water & m3 \\
\hline
\end{tabular}

*In principal these flows can also be considered as outputs, but from the ecoinvent structure they are under resources and hence considered inputs

571 Table 2: Default basic uncertainty information: dissipation factor k based on (Slob 1994) for the 572 water-related exchanges. 


\begin{tabular}{|c|c|c|c|c|}
\hline \multicolumn{2}{|l|}{ Basic uncertainty } & \multirow{2}{*}{$\begin{array}{c}\begin{array}{c}\text { combustion } \\
\text { emissions } \\
\mathbf{k}\end{array} \\
1.2\end{array}$} & \multirow{2}{*}{$\begin{array}{c}\begin{array}{c}\text { process } \\
\text { emissions } \\
\mathbf{k}\end{array} \\
1.2\end{array}$} & \multirow{2}{*}{$\begin{array}{c}\begin{array}{c}\text { agricultural } \\
\text { emissions } \\
\text { k }\end{array} \\
3.0\end{array}$} \\
\hline FromEnvironment & e.g. water, river & & & \\
\hline FromTechnosphere & $\begin{array}{l}\text { e.g. irrigation or tap } \\
\text { water }\end{array}$ & 1.1 & 1.1 & 1.1 \\
\hline ToEnvironment & water emitted to air & 1.5 & 1.5 & 3.0 \\
\hline ToEnvironment & $\begin{array}{l}\text { water emitted } \\
\text { (released) to water }\end{array}$ & 1.5 & 1.5 & 3.0 \\
\hline ToTechnosphere & wastewater & 1.1 & 1.1 & 1.1 \\
\hline
\end{tabular}

574

575

578

579

580

581

582

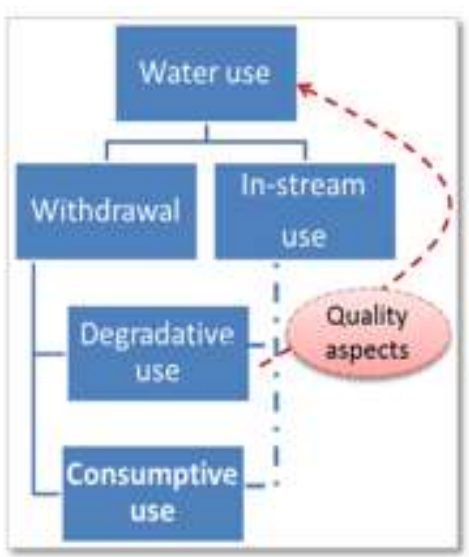

Inventory scheme
Count

Share

UPR total

Number of UPR that have no water flows

Water balance with $>15 \%$ deviation

7155

$100 \%$

2042

$29 \%$

Water balance with 5.0 - $15 \%$ deviation 2057 $29 \%$

Water balance with $0.1-5.0 \%$ deviation

686

Water balance with $<0.1 \%$ deviation

584 Figure 1: Concept for integrating water-use related environmental impacts in LCA (adopted from Pfister et al.,

585 2009): Life cycle inventory (LCI) data considers different types of water use: In-stream storage, consumptive use and

586 degradative use. Quality aspects, which are also important for water-reuse options, are covered by degradative use of 
587 freshwater (left graph). Based on the inventory scheme, the proposed impact assessment framework illustrates the 588 damages to three areas of protection (right graph).

589

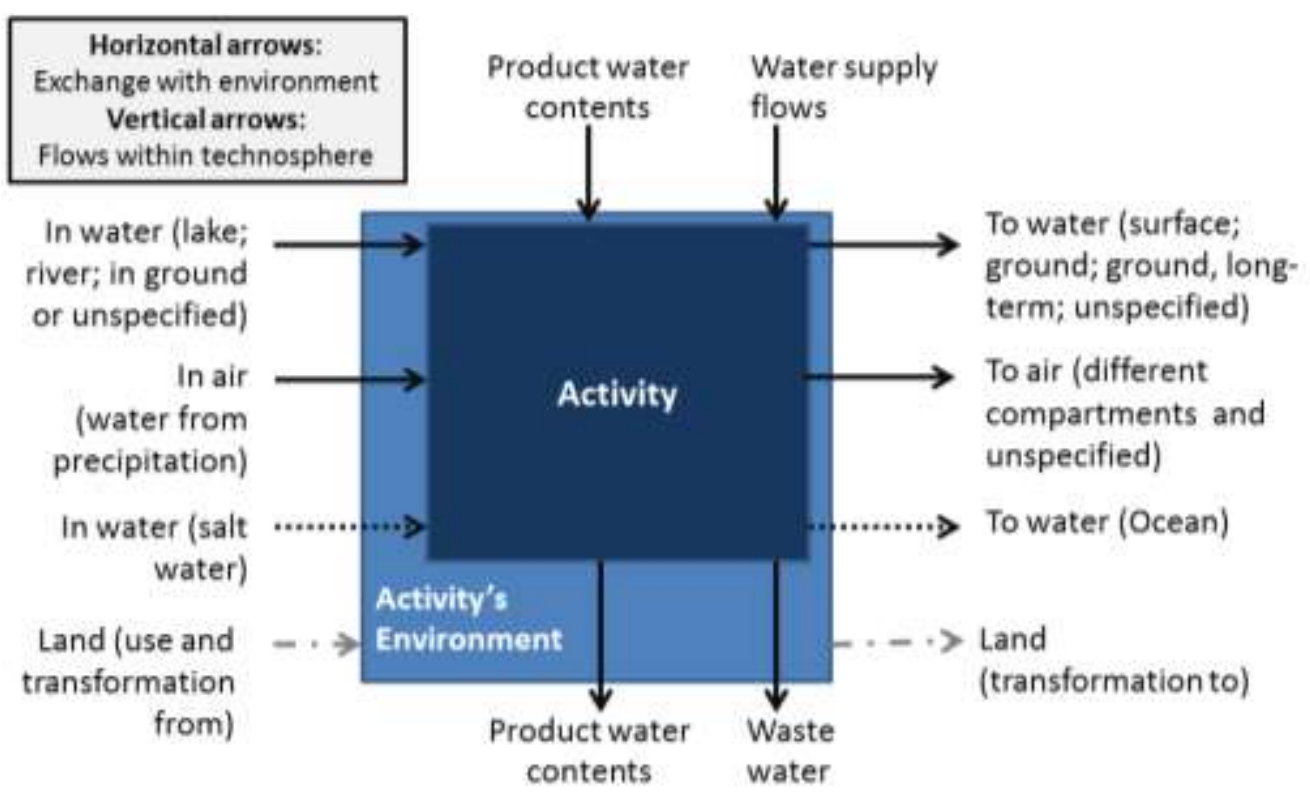

591 Figure 2: The horizontal flows are exchanges with the environment and the vertical flows are technosphere flows.

592 The activity box shows the system boundaries for the activity considered. For agricultural processes the activity's

593 environment is usually included in water management (i.e. the water flows of natural water supply from soil and

594 precipitation; also called "green water"). In ecoinvent, these flows are considered to happen outside the product system. Adapted from Pfister (2015). 

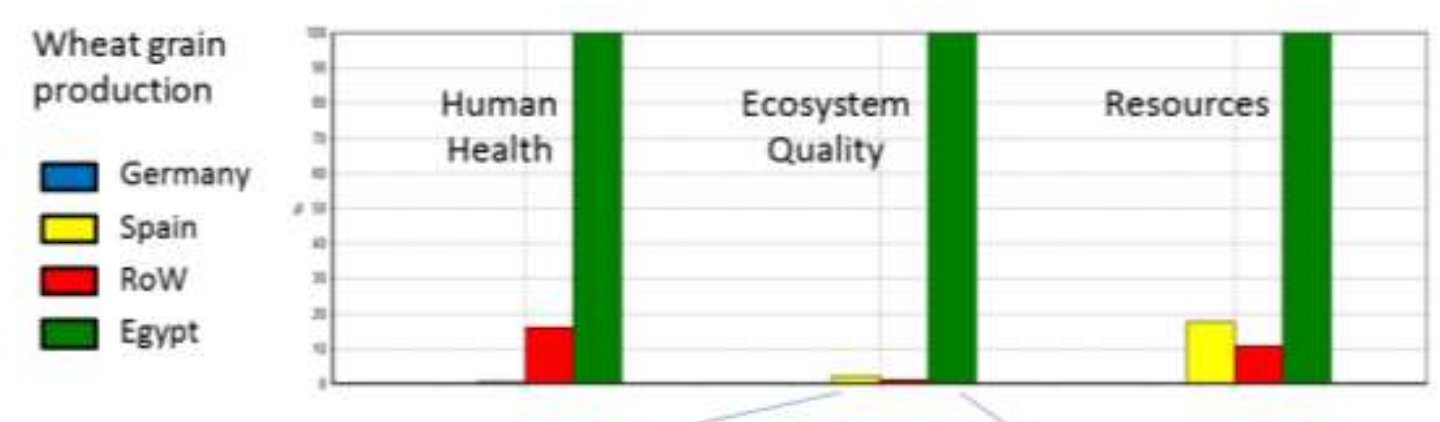

Spain: 2.7E-09 species * year $/ \mathrm{kg}$

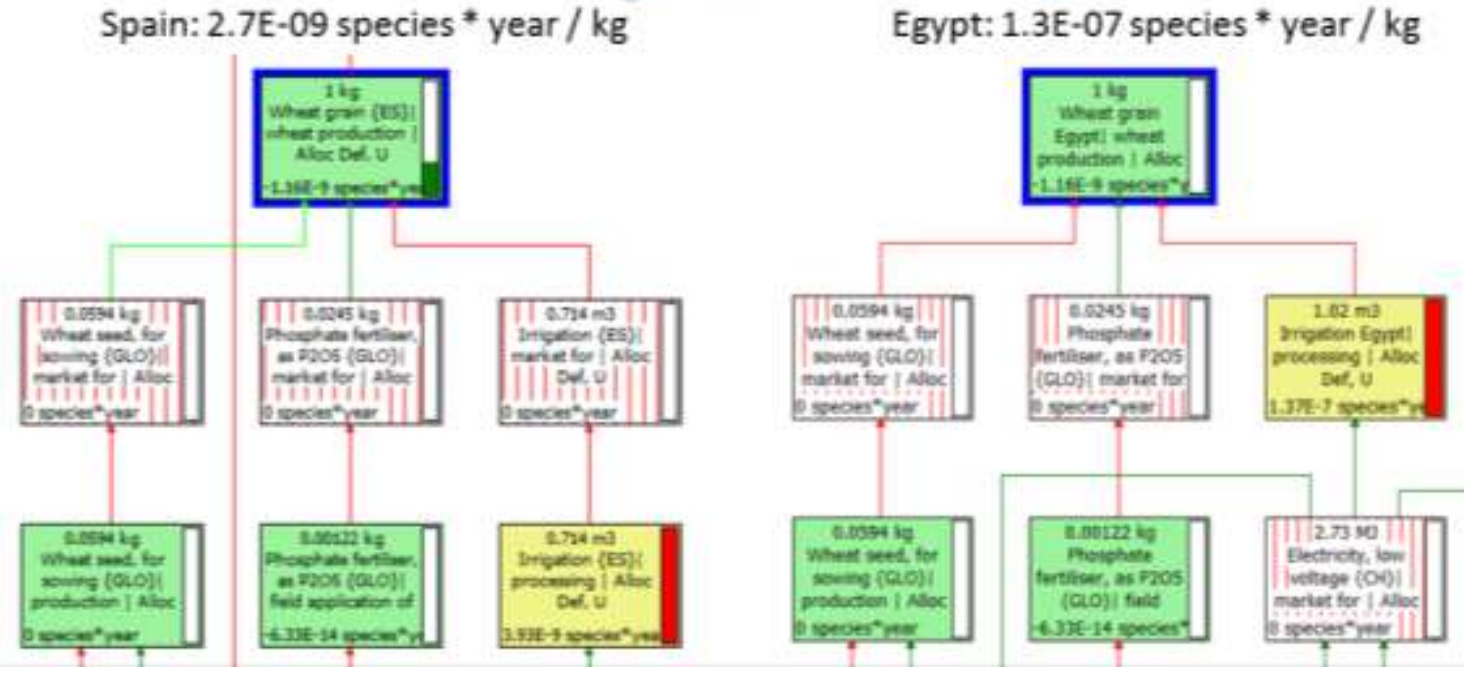

598 Figure 3: Comparison of LCIA results of water consumption in ReCiPe units (Goedkoop et al. 2009, Pfister et al.

599 2011a) based on irrigation data from Pfister et al. (2011b) for wheat grain production: Spain, Germany and Rest of 600 the World (RoW) have respective activities present in ecoinvent v3.1, and for Egypt it has been created in SimaPro 6018.04 as a copy of Spanish activity. 


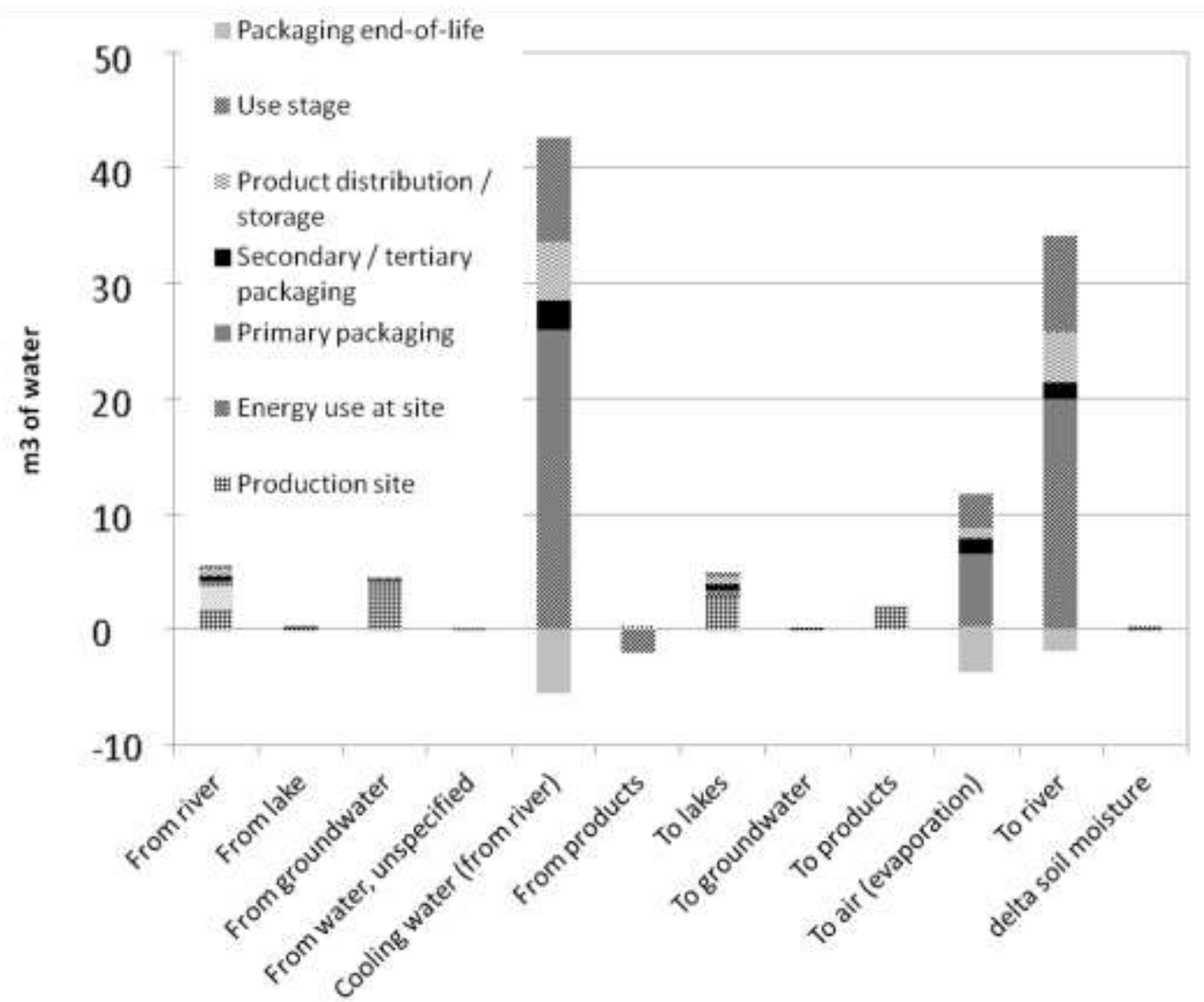

603

604 Figure 4: Inventory analysis in the assessment of a litre of bottled water in France. The flows are attributed to life cycle stages in order to provide more information on where to focus detailed assessments in the supply chain. 